\title{
A contribution on versatile process chains: joining with adaptive joining elements, formed by friction spinning
}

\author{
Christian Wischer $^{1}$ (D) . Werner Homberg ${ }^{1}$
}

Received: 15 October 2021 / Accepted: 29 November 2021 / Published online: 23 December 2021

(c) The Author(s) 2021

\begin{abstract}
Nowadays, manufacturing of multi-material structures requires a variety of mechanical joining techniques. Mechanical joining processes and joining elements are used to meet a wide range of requirements, especially on versatile process chains. Most of these are explicitly adapted to only one, specific application. This leads to a less flexibility process chain due to many different variants and high costs. Changes in the boundary conditions like sheet thickness, or layers, lead to a need of re-design over the process and thus to a loss of time. To overcome this drawback, an innovative approach can be the use of individually manufactured and application-adapted joining elements (JE), the so-called Friction Spun Joint Connectors (FSJC). This new approach is based on defined, friction-induced heat input during the manufacturing and joining of the FSJC. This effect increases the formability of the initial material locally and permits them to be explicitly adapted to its application area. To gain a more detailed insight into the new process design, this paper presents a detailed characterization of the new joining technique with adaptive joining elements. The effects and interactions of relevant process variables onto the course and joining result is presented and described. The joining process comprises two stages: the manufacturing of FSJC from uniform initial material and the adaptive joining process itself. The following contribution presents the results of ongoing research work and includes the process concept, process properties and the results of experimental investigations. New promising concepts are presented and further specified. These approaches utilize the current knowledge and expand it systematically to open new fields of application.
\end{abstract}

Keywords Friction spinning $\cdot$ Versatile process chain $\cdot$ Friction riveting $\cdot$ Mechanical joining

\section{Introduction and current state of research}

Production technology is currently facing immense challenges. Society's growing sense of climate protection is placing new demands on future products. Particularly extensive transformations are necessary for automotive engineering. Furthermore, an increasing number of governments are deciding to end the use of the combustion engine and impose more stringent regulations [1]. One key factor in reducing the necessary energy requirements is a lightweight construction. Nevertheless, this approach also leads to various technical challenges related to joining technology [2-5].

Thermal bonding techniques quickly reach their limits joining dissimilar materials and varying sheet thicknesses.

Christian Wischer

cw@luf.upb.de

1 Forming and Machining Technology, Paderborn University, Warburger Str. 100, 33098 Paderborn, Germany
Furthermore, the thermal heat input has a local effect on the material and lowers the mechanical strengths. Alternative thermomechanical processes such as friction stir welding are suitable for producing dissimilar joints with decreased temperature input. This technique is often used to join sheet materials by material bonding. Despite a considerable increase in knowledge and a quite large expansion of the process limits, this joining technology has unfortunately not been fully established for various factors. Big process forces occur, which place particular demands on the clamping and require a sufficient degree of stiffness of the sheet materials tools, fixtures and machine tools [6].

Processes suitable for fulfilling the requirements of modern lightweight construction are mechanical joining technologies (Fig. 1). These can join dissimilar materials without thermal heat input and its adverse effects on strength [7-10].

Some joining techniques require an additional joining element to create the connection, and others do not. Furthermore, the techniques differ in terms of the required 


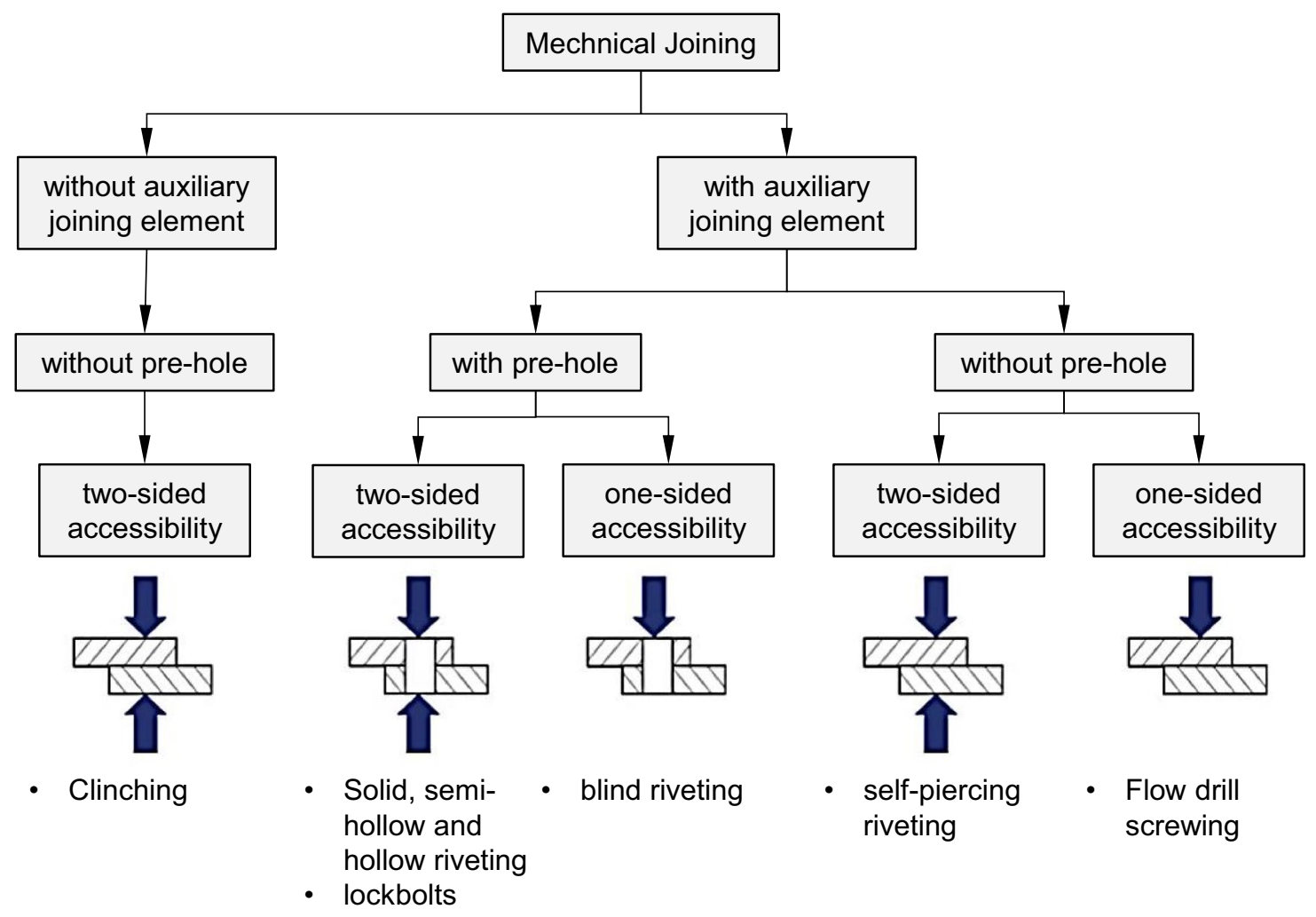

Fig. 1 Classification of mechanical joining methods according to DIN 8593-5:2003-09

accessibility to the joining spot. Also, the different processes impose different requirements on the ductility of the joining partners. Pre-Hole free clinching requires at least one ductile component because of the high deformation degree on the die and punch side. Local changes in sheet thickness or layers, cannot be implemented without costly tool and process control adaptations [7, 8, 11]. Methods with auxiliary joining elements pierce the components partially or entirely, with or without pre-hole, to form the load bearing interlock. In most cases the elements are specially adapted to the requirements of their set point in shape and surface properties [12]. Modern lightweight structures lead to a large number of set points with a significantly different requirement profile and thus require many different types of auxiliary joining elements. Hundreds of different self-piercing rivets can be found in a car body without even counting other processes [13].

Of interest in industrial applications are specially methods that enable pre-hole-free joints with only one-sided accessibility to the joining spot. Such is represented by flowdrill-screwing. This method uses friction-induced heat to drive through components to join them. The connection is created by a rotating nail-shaped auxiliary joining element penetrating the sheets. Subsequently a thread is formed into the resulting draught, either by the element. Due to these properties and its good automatability this method is widely used especially in profile-intensive car body construction $[1,3]$. However, the investigations of [14] and [15] indicate that pre-hole-free joints are possible but that the components tend to delaminate. A partial pre-holing of the cover sheet is common, especially in the case of intended fiber composites to fix this issue $[15,16]$. However, this additional step reduces the efficiency of the process and increases the operating expense. Flow drill screwing is not the only process that uses friction-induced heat to join components together. Friction welding, for example, creates a material bond between the auxiliary joining element and the base plate. The connection created is not detachable and requires a base plate of the same material as the JE [17, 18]. Reference [19] use a rotating $\mathrm{JE}$ in the shape of an self-piercing rivet to create frictional heat while drive-through sheets. This technique creates a partly welded but also mechanically bonded connection. Reference [20] developed an approach to join pre-holed titanium sheets by guiding a rotating die on the tip of a bolt to form a spherical closing head by friction induced heat. All processes have in common that the JE mostly can be used at a limited range of different joining tasks. A different joining spot requires a new type of auxiliary joining element und leads to an increased number of different JE to assembly a whole structure [16].

One possibility to stop this development are adaptive joining elements formed by friction spinning. This 
innovative approach uses uniform initial material to form a tailored element with friction-induced heat. Due to the local temperature increase of the adaptive joining element, a large interlock and thus strength can be achieved. Each $\mathrm{JE}$ is independently adjustable in length and diameter so that modifications to the sheet thickness and required sheet thickness can be implemented at any time. In addition, the manufacturing of such an element can be process-integrated, thus reducing the cost and logistics providing the elements throughout the process chain. This method offers the possibility to join imprecisely positioned components without pre-holed components. Thus decreases the complexity of the joining process. To overcome the limitations of conventional mechanical joining as the need for precisely positioned preholed components or ductile materials [7, 8, 11, 13, 21], joining with adaptive joining elements was investigated and promising results presented below. Special attention is paid to the adaptability of the process. For this purpose, selected influences on the properties of the joining element or the joint are shown. Various problems of conventional joining processes are listed and how adaptive auxiliary joining elements can fulfill these requirements of lightweight construction.

\section{Process stages joining with adaptive joining elements}

Describing the process sequence of joining with adaptive friction elements requires a profound knowledge of the acting mechanisms. The novel joining process uses frictioninduced heat to modify the shape of an initial metal part.
The relative movement among a rotating semi-finished product and a stationary tool generates the necessary heat. As a result, the flow stresses and thus the forces required for forming are reduced. In addition, temperature influences the internal metallic structure of the material, as [22-24] demonstrated in their investigations. Figure 1 illustrates that the joining process comprises a total of two stages. The first stage (Fig. 2a) includes the generation of adaptive auxiliary joining elements. The second (Fig. 2c) is the joining process using adaptive joining elements to join sheet materials. The essential tool setup is shown on the left side, positioning the angled tool and the semi-finished product (SFP). Centered, an overview of possible geometries and general boundary conditions are depicted (Fig. 2b).

To study the characteristics of the rivets, extensive analysis of the cross-section is required. Consequently, initial shaft of the initial material was not removed, otherwise they would not be feasible to produce. In the process sequence of the 2 stage, a mechanical separation step is provided. All experimental results are generated using the experimental setup at the LUF, displayed in Fig. 3. This rig is adaptable to the requirements of the intended investigations, e.g., setup for different specimens, geometries or cooling options. A particular component is a specially designed milling spindle 180,677 from Weiss Spindeltechnologie, Maroldsweisach, Germany. It provides speeds of up to 14.000 revolutions per minute and includes an HSK-A63 tool interface. Furthermore, to meet the requirements of mechanical joining technology, the bearing of the spindle system was adapted to withstand an increased axial load of at least $10 \mathrm{kN}$. This value is suitable for the manufacturing of the FSJC and the joining process under given boundary conditions. To provide

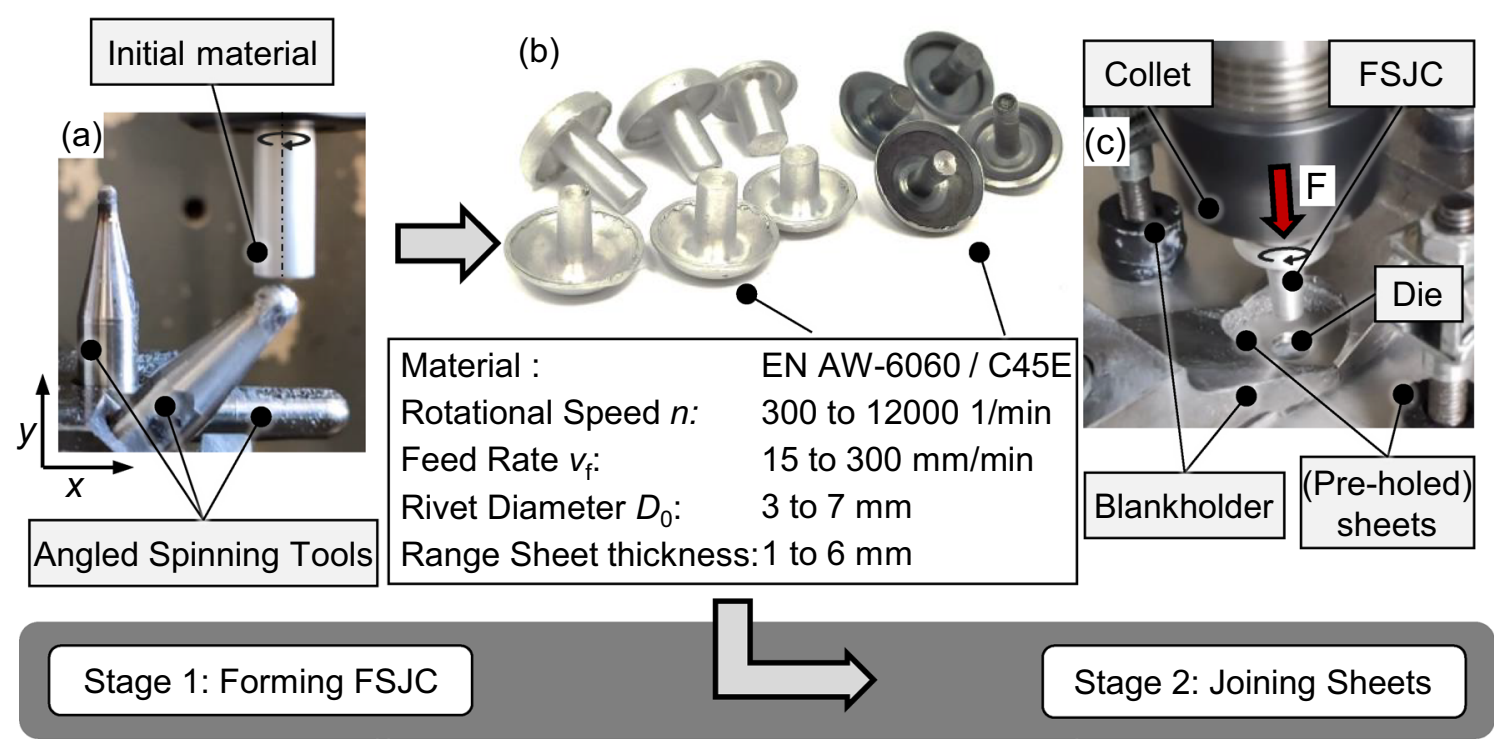

Fig. 2 Process stages for joining with adaptive friction spun joint connectors (FSJC) 


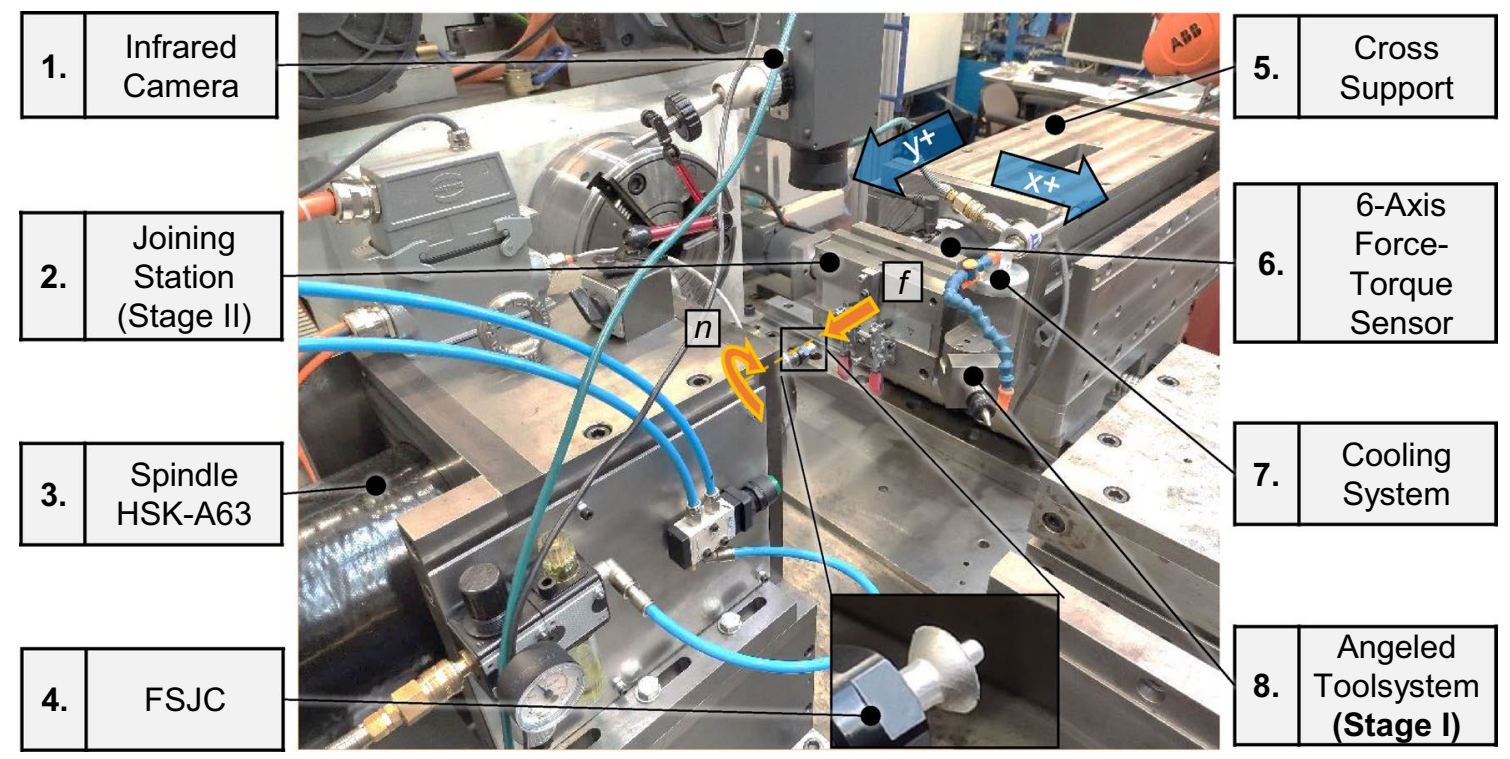

Fig. 3 Experimental setup

more flexibility in the process design, the spindle setup (Figs. 3, 4, 5) is integrated into the control system Siemens Sinumerik 840SL. NC-controlled cross support performs the positioning movements in the $X$ and $Y$ directions. To manufacture the adaptive joining elements and to join components together, suitable fixtures are required.

One is shown on the front side of the support in Fig. 3 to manufacture lap shear specimen. The jig can be exchanged for others, e.g., to investigate the upsetting behavior of different materials. To form the FSJC and join them, the setup includes an angle-adjustable spinning tool (Fig. 3 right) required for the first stage and a joining device and clamping system for the second stage. An appropriate load cell is provided to record the acting process forces during the process phases. It is located below the joining station of the assembly. It enables process-integrated recording of the acting forces and torques during the joining and generation of the adaptive joining elements.

The strain measurement force transducer from ME Systems technology K6D175 50kN/5kNm/UP13 converts the acting force and torque into an electrical signal. The values are amplified by an HBM data-acquisition system (QuantumX Module MX440B) and recorded by an additional computer. Due to the measurements, influences of the acting process parameters can be analyzed to optimize the process and tool design. An additional process parameter is the effective temperature during the generation of the FSJC and the joining process. To determine and evaluate temperatures

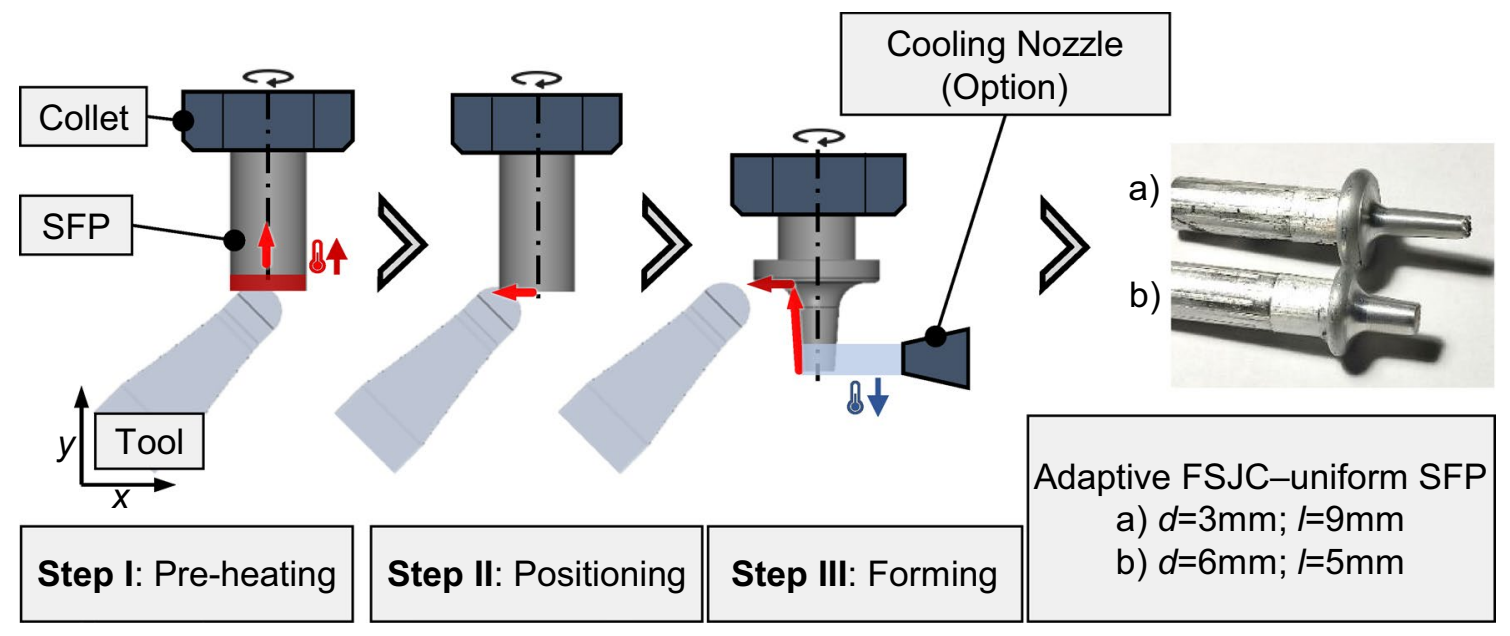

Fig. 4 Process principle forming adaptive joining elements 


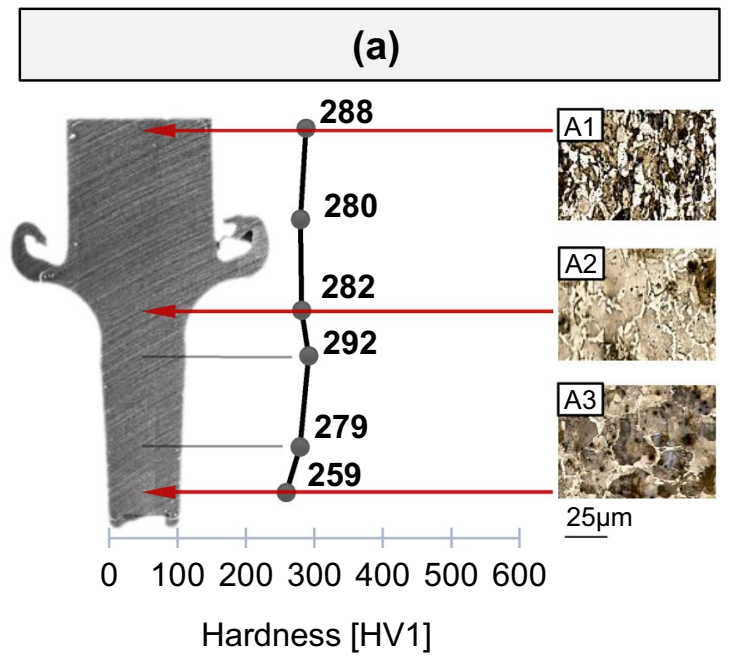

Fig. 5 Comparison of the influence of local tempering on the hardness and microstructure of an adaptive joining element made of C45E-Initial diameter $d_{0}=8 \mathrm{~mm}$, FSJC diameter $d_{1}=5 \mathrm{~mm}$, length

an infrared camera from the company Infratech VarioCAM $\mathrm{hr}$ head is mounted above the spindle. This data allows a qualitative measurement about the acting temperatures on the workpiece surface. The curves can be used to evaluate and analyze the influence of varying process parameters on the temperature input to derive process control strategies. On the tool side, rod-shaped universal tools are used, which are characterized by contour flexibility (Figs. 3, 6, 7, 8). These are exchangeable since a collet chuck fixes them. A material that is resistant to temperature is of decisive importance for successful processing. Due to the higher acting temperatures, carbide tools are required to form and join suitable steel rivets. For aluminum, tool steels are sufficient because

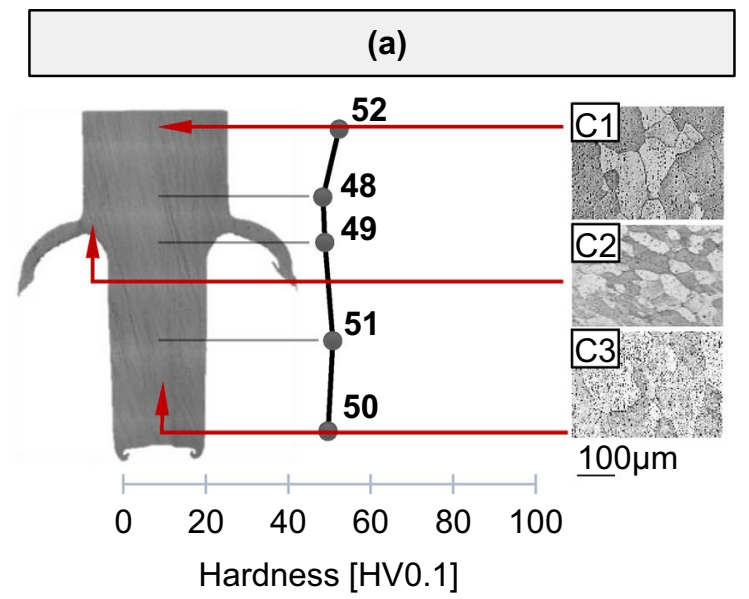

Fig. 6 Comparison of the influence of local tempering on the hardness and microstructure of an adaptive joining element made of EN AW 6060-T6 Initial diameter $d_{0}=8 \mathrm{~mm}$, FSJC diameter $d_{1}=5 \mathrm{~mm}$,

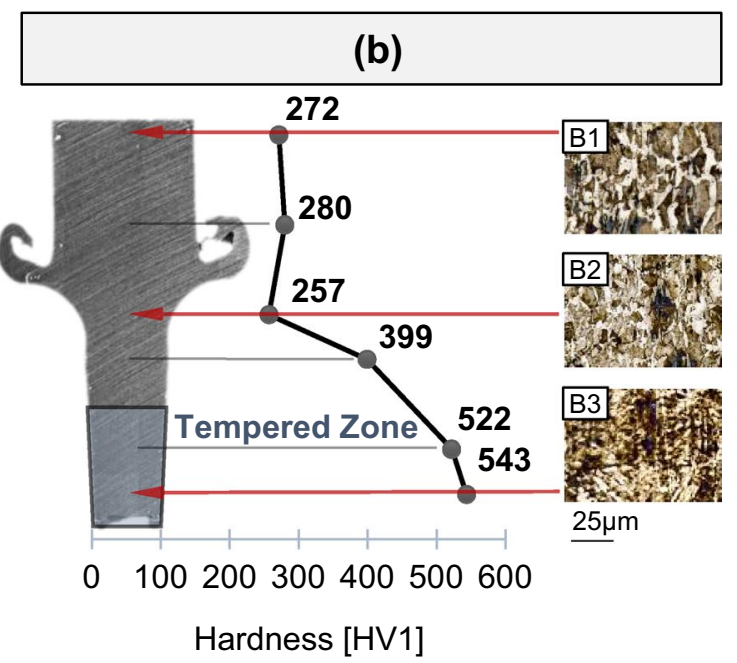

$9 \mathrm{~mm}$-Process parameters: a $n=4000 \mathrm{~min}^{-1}, f=20 \mathrm{~mm} / \mathrm{min}, \mathbf{b}$ $n=4000 \mathrm{~min}^{-1}, f=20 \mathrm{~mm} / \mathrm{min}$, tip immersed in water for $5 \mathrm{~s}$

of the significantly lower temperatures in the forming phase. In the following, the two stages of joining with adaptive reaming elements are introduced and explained.

\section{Stage I: forming adaptive joining elements}

At the beginning of the first stage (Fig. 1a) in the process sequence, the adaptive FSJC are formed. The presented process is not location-bound and can be carried out process integrated, anywhere in the world independently of the joining process. Delivery times are reduced and only a simple

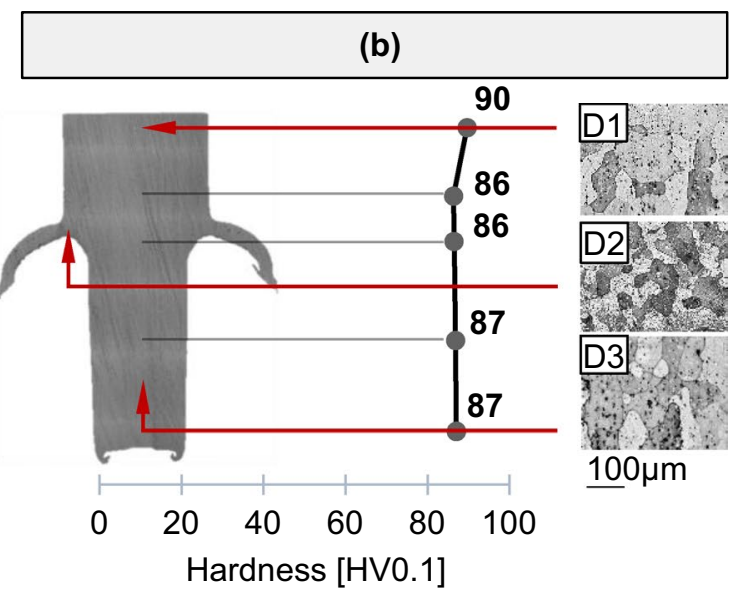

length $9 \mathrm{~mm}$ - Process parameter: a $n=2000 \mathrm{~min}^{-1}, f=50 \mathrm{~mm} / \mathrm{min}$, b $n=2000 \mathrm{~min}^{-1}, f=600 \mathrm{~mm} / \mathrm{min}$ 


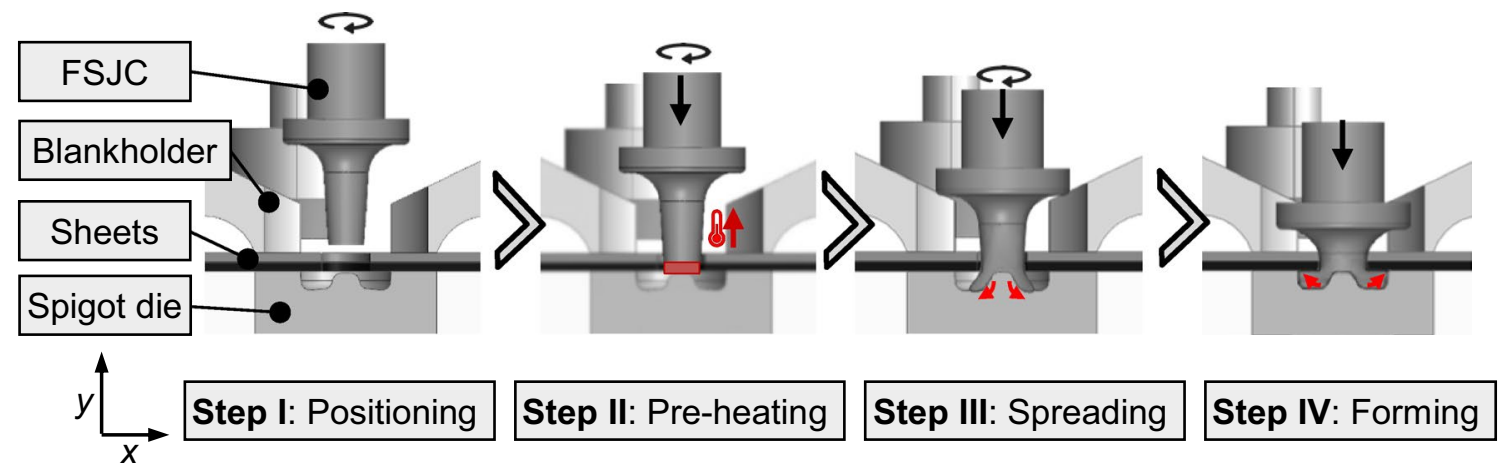

Fig. 7 Process principle joining with FSJC

(a)

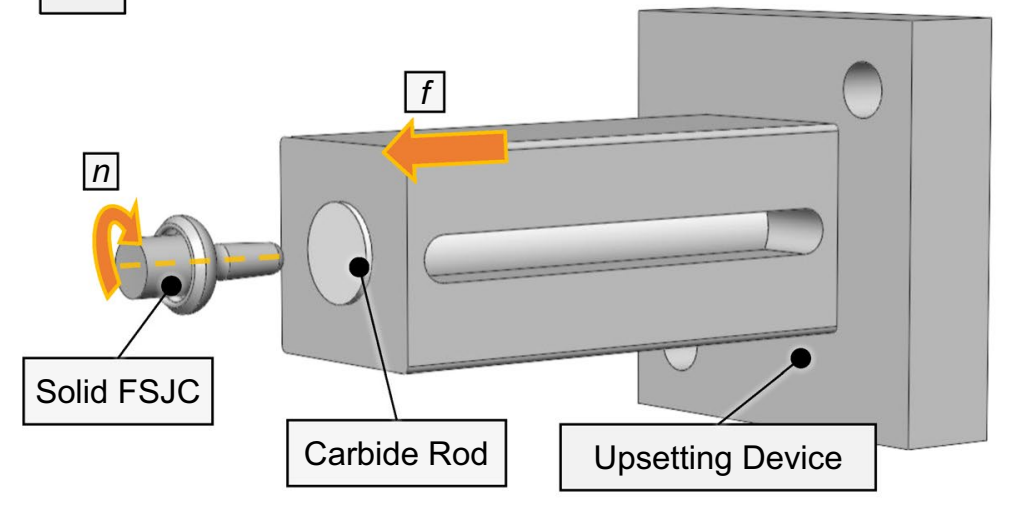

(b)

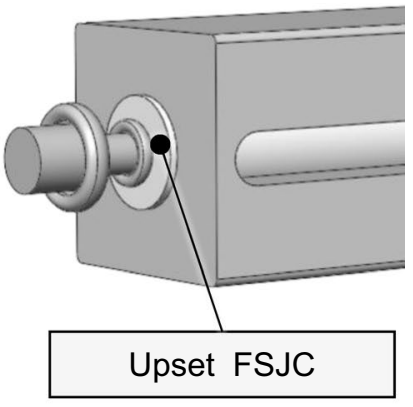

Fig. 8 Experimental set-up to investigate the upsetting characteristics of FSJC

and low-cost initial material is required allowing to be less dependent less dependent on the few manufacturers Especially in volatile supply chains and the just-in-time approach, this is a decisive advantage compared to other joining methods. Furthermore, Adaptations to the respective joining task can be implemented immediately. The general sequence of the manufacturing process is shown in Fig. 4.

Each cycle starts with the relative positioning of the rotating circular semi-finished product (SFP) to the attached angled universal tool (i). Subsequently, the tip of the tool immerses into the semi-finished product (ii). The relative movement pre-heat its tip by frictional heat and increases the formability of the SFP. Followed in the third step: the final forming of the connector's geometry. The FSJCs length and diameter are formed by a relative movement parallel to the rotational axis (iii). Finally, the tool is separated from the element by a downward movement and is ready to be used in the following second process stage for joining components. Optionally, process-integrated hardening procedures are possible after the third step, to harden the joining element locally. This option requires intensive cooling of the workpiece e.g., by locally applying a cooling medium via a nozzle system. This option provides a different control variable for adapting the auxiliary joining elements to their intended use, penetrating sheet materials, or increasing the connection strength.

\section{Mechanical properties of adaptively formed FSJC}

The basic mechanism of using friction-induced heat to reduce flow stresses locally is not bound to a specific metal. The aluminum alloy EN AW 6060-T6, widely used in many applications, and C45E steel have been extensively investigated. In order to increase the hardness of the steel joining element, hardening procedures are necessary. According to Fig. 4, cooling mediums are supplied via nozzles to achieve the required cooling rates. Both displayed elements are being formed from the same initial material diameter of $8 \mathrm{~mm}$ and process parameters. The tempered element Fig. $5 \mathrm{~b}$ on the right has been immersed in water for $5 \mathrm{~s}$ and the element 
Fig. 5a at ambient temperature. This depicts the Vickers hardness plot over the length of the adaptive joint, supplemented by images presenting the microstructure. The effect of heat treatment is visible. On the one hand, by the hardness, and on the other hand by the type of microstructure in the FSJC shaft. The hardness level in the deformation zone of the partially hardened element (B3) is significantly increased compared to the unhardened one (A3). Apparent differences are also visible when observing the resulting microstructures. As expected, the hardened element has a distinct tempered microstructure (B3). A different result can be seen for the element tempered at ambient temperature. The corresponding figure A3 shows an evident grain growth compared to the initial microstructure in A1. This is due to the longer holding time of the temperature, which results in a coarser microstructure and less hard material. Both properties can be used advantageously to fulfill different requirements on the joint in terms of ductility or strength. In A2 and B2, an initial recrystallization process can be identified and no specific grains orientation.

From the perspective of lightweight construction, aluminum alloys are of interest since this material has considerable lightweight construction potential due to its quite low density. However different mechanical properties can be achieved due to the process control: the hardness is influenced by the process parameters. If aluminum EN AW 6060T6 is formed, a reduction in hardness can be determined in the forming zone (Fig. 6a). Based on the presented data shown in Fig. 6, a low feed rate displayed on the left in combination with a high rotational speed result in a high reduction in hardness. Renewed temperature input during the forming of the adaptive joining elements leads the material to an untampered condition. The hardness of the initial material of approx. $87 \mathrm{HV}$ has been reduced to a value of $50 \mathrm{HV}$.

These results are consistent with the results obtained by [13] investigations of friction spun tubular SFP. Compared with the initial microstructure C1/D1, alike slightly coarsergrained (C3/D3) microstructure can be identified in the rivet's shaft. A refined microstructure can be noticed in the direct forming zone. In the other areas, almost the original structure is visible. The hardness values in Fig. $6 \mathrm{~b}$ indicate only a slight decrease in hardness compared to the initial properties. The reason could be found in the higher feed rate. Due to the short process time, less heat is transferred into the material. Consequently, the hardening deposits of the heat treatment are not reduced, and the hardness remains.

In summary, the aluminum alloy EN AW 6060-T6 offers a wide range for adjustments of the mechanical strength in the first stage by process parameter variation. The option to maintain the initial hardness and thus the materials strength opens further possibilities for adaptive process control. Another effective parameter for specifically influencing the strength of the joint is to modify the rivet dimensions in terms of diameter and overall length. Both dimensions are adaptable to the requirements of the joining spot. A larger rivet diameter increases the cross-section of the rivet and thus the shear-tensile strength, but also weight of the final joint. The FSJC lends itself to optimization in terms of maximum shear tensile strength or lightweight, depending on the requirements. The properties of the joints are directly adaptable from joint to joint as the elements are individually manufactured. In addition to the modification of the rivet diameter, the second variable is the length of the FSJC. Adaptations to the sheet thickness can be implemented from one connection to another, differentiating the presented technique from conventional mechanical joining processes.

\section{Stage II: joining with FSJC}

The second stage joining with adaptive friction elements also benefits from friction-induced heat on process control and joint properties. The joining process is directly integrated into the process after the generation of the adaptive joining element (Stage I). The sequence is shown in Fig. 7 using the pre-holed sheets example and presented in more detail below.

Each joining cycle starts by positioning the adaptive joining element coaxially at its intended position (Step I). Subsequently, the rotating element underneath the base plate is positioned immediately above the die (Step II), followed by the third step, spreading. The joining element starts to rotate and is pressed onto a fixed die. The relative movement between both components generates frictional heat and preheat the rivets base. Finally, the interlock is formed, decisive for the connections load-bearing capacity. The FSJC is pressed into the die's cavity by a coaxial feed stroke. After the final position has been reached, spindle rotation and feed movement stop immediately, and disassembly can occur. Especially in the processing of aluminum alloys, an optional fifth step is recommended, repositioning the FSJC again into the die's cavity. This additional feed stroke upsets the rivets shaft, increases the pressure inside the hole and thus the frictional connection and stiffness. A decisive aspect for a successful joining process occurs in the die design. Aluminum alloys tend to buckle during the third step (Fig. 7 Step III) and leads to an incorrectly connection. A modification in die design solves this issue. A spigot die guides the material to the outer edge of the die and provides coaxially between the two components during the joining process [16].

\subsection{Joining properties of steel FSJC}

Steel joining elements show no tendency to buckle so al less complex die design is required. The reason may find the different material-specific values. Aluminum conducts 
heat much faster into the base material, reducing the flow stresses and thus the strength over a wider range. An initial process characterization of joining with steel auxiliary joining elements, demonstrates differing material behavior and represents the third step of the joining step.

The experimental data were obtained on the test rig using an upsetting device (Fig. 8). This device is used to investigate the behavior specifically, without the limiting effect of pre-holed sheets. A rotating, adaptive joining element is pressed against an upsetting plate made of carbide in accordance with the process sequence in Fig. 7. This separate investigation provides conclusions for future process control strategies and the effect of further heat treatment and deformation on the expected joint properties. Figure 9 compares the influence of an additional upsetting phase on geometric shape, hardness, and micrographic structure. The FSJC were formed according the process parameters in Figs. 5a and 6a and possess the shown mechanical properties. As Fig. 9a presents aluminum tends to upset over a larger area until it bucks off to any side without the limiting and guiding effect of pre-holed sheets [5]. Steel expands, specifically the tip of the joining element (Fig. 9b.).

The upsetting process also affects the mechanical properties of the FSJC. This is mostly the locally increased deformation degree above the die and the associated grain refinement and hardening of the material on its tip (Fig. 9). Upsetting EN AW 6060-T6 FSJC, no further de- or increase in hardness is observed (Fig. 9a). However, compared to the structures obtained, a significantly more refined structure is evident in the direct contact zone (E1 to E2) according to [22]. In the case of the displayed non-hardened steel tip, a further deformation by upsetting leads to transforming of the microstructure. As a result, the coarse microstructure F1 is transformed into a bainitic structure F2, leading to a slightly

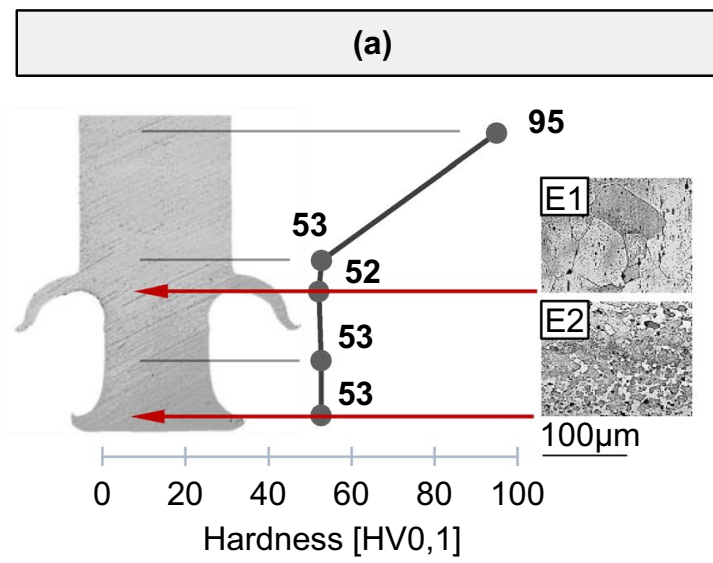

Fig. 9 Comparison of the upsetting behavior of EN AW 6060-T6 (left) and C45E (right) FSJC and its influence on hardness and microstructure-Initial diameter $d_{0}=8 \mathrm{~mm}$, FSJC diameter $d_{1}=5 \mathrm{~mm}$, hardened tip compared to the initial values and higher yield strength [25].

Summarized-during the joining stage, the material is deformed, and the hardness and grain size is affected over the processing time. The values are adjustable via process parameter modification depending on the requirements placed on the joint.

\section{Summary}

Joining with adaptive joining elements offers a wide range of opportunities to fulfill the demanding requirements of modern lightweight construction. The presented process variables allow the individual properties of each joint the requirements to be adjusted to withstand the load regarding the best possible lightweight design. This is possible by modifying the load-bearing diameter and the length of the rivet. The FSJC length enables adaption to the local thickness of the workpiece or components. Adjustments of the mechanical properties are feasible by selecting the process parameters during the corresponding process steps. Depending on the requirements of the connection, this can be designed regarding maximum strength or ductility. In the case of tempered aluminum alloys such as EN AW 6060-T6, the temperature input due to the applied rotational speed and feed rate is decisive for the hardness of the rivet and the final strength of the joint. Adaptive joining elements made of treatable materials such as steel offer potential for producing pre-hole-free joints. These offer further options in process control, the possibility of process-integrated local hardening. The process offers the possibility of forming a wide variety of rivets from a uniform starting material.

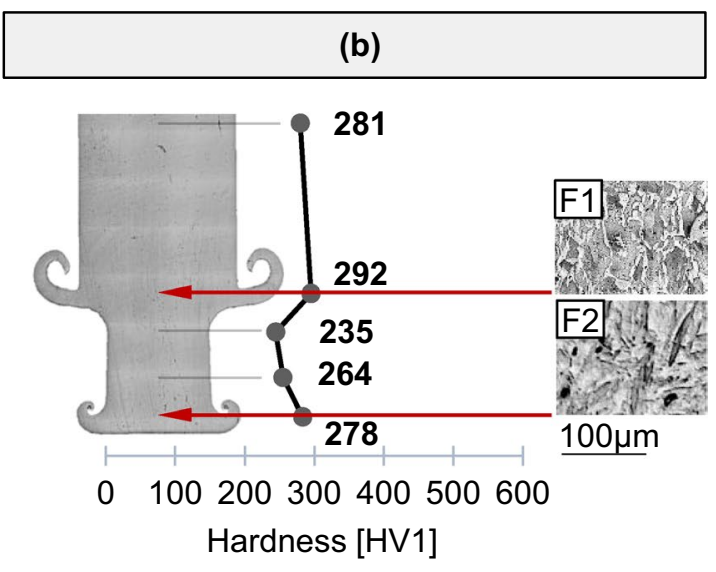

length $9 \mathrm{~mm}$, Upsetting distance $2 \mathrm{~mm}$-Process parameters: $n=10$ $000 \mathrm{~min}^{-1}, f=150 \mathrm{~mm} / \mathrm{min}$ 


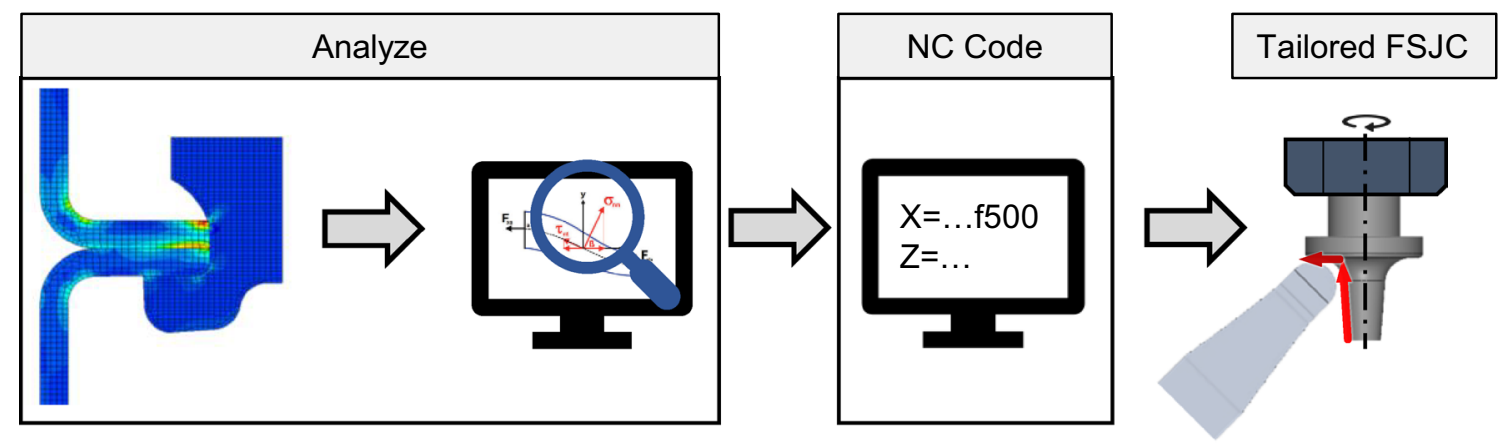

Fig. 10 Novel process chain based on adaptive joining elements formed by friction spinning

\section{Outlook}

From the effects of the process variables presented in this paper, approaches are derivable for the consistent further development of joining with adaptive friction elements. It is of decisive importance to further develop pre-holefree joining with adaptive friction elements. This will be achieved by a comprehensive characterization of the joining process with steel adaptive joining elements. Extensive investigations will address the development of a suitable process control strategy and a characterization of the joining properties under different load profiles. Due to this flexibility, the process is particularly suitable for individual to small series production. With increased knowledge, the process times will also decrease, and the economic efficiency will increase. The flexibility in the process design to create pre-hole-free as well as pre-hole-contaminated connections will position the process apart from mechanical joining processes.

In the long term, the aim is to integrate the novel technique into the entire process chain (Fig. 10). Flexibility can be exploited at an early stage of the development process to design suitable products to withstand specific loads. Analyze the load transfer via FE techniques will define the boundary conditions of each connection. Accordingly, the necessary joining elements are designed separately from the joining process. An intelligent post-processor for joining adaptive joining elements would offer added value. According to the boundary conditions, appropriate elements could be suggested to meet the requirements of the connection. NC command code will be automatically derived and transferred to a manufacturing cell to form customized auxiliary joining elements by friction spinning. Concluding, joining with adaptive FSJC will make an effective contribution to versatile process chains.

Acknowledgements The authors would like to thank the DFG (German Research Foundation) for funding the TRR 285 -Project-ID 418701707, subproject C03.
Funding Open Access funding enabled and organized by Projekt DEAL.

Open Access This article is licensed under a Creative Commons Attribution 4.0 International License, which permits use, sharing, adaptation, distribution and reproduction in any medium or format, as long as you give appropriate credit to the original author(s) and the source, provide a link to the Creative Commons licence, and indicate if changes were made. The images or other third party material in this article are included in the article's Creative Commons licence, unless indicated otherwise in a credit line to the material. If material is not included in the article's Creative Commons licence and your intended use is not permitted by statutory regulation or exceeds the permitted use, you will need to obtain permission directly from the copyright holder. To view a copy of this licence, visit http://creativecommons.org/licenses/by/4.0/.

\section{References}

1. Taub A, De Moor E, Luo A, Matlock DK, Speer JG, Vaidya U (2019) Materials for automotive lightweighting. Annu Rev Mater Res 49:327-359. https://doi.org/10.1146/annur ev-matsci-070218-010134

2. Hirschab J, Al-Samman T (2013) Superior light metals by texture engineering: optimized aluminum and magnesium alloys for automotive applications. Acta Mater 61(3):818-843. https:// doi.org/10.1016/j.actamat.2012.10.044

3. Mallick K (2012) Advanced materials for automotive applications: an overview. In: Rowe J (ed) Advanced materials in automotive engineering. Woodhead Publishing, Oxford, pp 5-27. https://doi.org/10.1533/9780857095466.5

4. Merklein M, Johannes M, Lechner M, Kuppert A (2014) A review on tailored blanks-Production, applications and evaluation. J Mater Process Technol 214(2):151-164. https://doi.org/ 10.1016/j.jmatprotec.2013.08.015

5. Wischer C, Wiens E, Homberg W (2021) Joining with versatile joining elements formed by friction spinning. J Adv Join Process. https://doi.org/10.1016/j.jajp.2021.100060

6. Çam G, Mistikoglu S (2014) Recent developments in friction stir welding of Al-alloys. J Mater Eng Perform 23:1936-1953. https://doi.org/10.1007/s11665-014-0968-x

7. Salamati M, Soltanpour M, Fazli A, Zajkani A (2019) Processing and tooling considerations in joining by forming technologies; part A-mechanical joining. Int J Adv Manuf Technol 101:261-315. https://doi.org/10.1007/s00170-018-2823-y 
8. Geoffrey D (2012) Materials for automobile bodies. Kap.6: Component assembly: materials joining technology. Elsevier, pp 17-91. https://doi.org/10.1016/B978-0-08-096979-4.00006-2

9. Martinsen K, Hu SJ, Carlson BE (2015) Joining of dissimilar materials. CIRP Ann 64(2):679-699. https://doi.org/10.1016/j. cirp.2015.05.006

10. Ng M-K, Li L, Fan Z, Gao RX, Smith EF, Ehmann KF, Cao J (2015) Joining sheet metals by electrically-assisted roll bonding. CIRP Ann 64(1):273-276. https://doi.org/10.1016/j.cirp. 2015.04.13

11. Mori K, Bay N, Fratini L, Micari F, Tekkaya AE (2013) Joining by plastic deformation. CIRP Ann Manuf Technol 62:673-694. https://doi.org/10.1016/j.cirp.2013.05.004

12. Baptista RJS, Pragana JPM, Bragança IMF, Silva CMA, Martins PAF (2020) Joining metal-polymer sandwich composite sheets with mechanical nuggets. CIRP Ann. https://doi.org/10.1016/j. cirp.2020.03.008

13. Pragana JPM, Silva CMA, Bragança IMF, Alves LM, Martins PAF (2018) A new joining by forming process to produce lap joints in metal sheets. CIRP Ann 67(1):301-304. https://doi.org/ 10.1016/j.cirp.2018.04.121

14. Geoffrey D (2012) Materials for automobile bodies. Kap.2: Design and material utilization. Elsevier, pp 17-91. https://doi.org/10. 1016/B978-0-08-096979-4.00002-5

15. Costas M, Morin D, Sønstab $\varnothing$ JK, Langseth M (2021) On the effect of pilot holes on the mechanical behaviour of flow-drill screw joints. Experimental tests and mesoscale numerical simulations. J Mater Process Technol 294:117133. https://doi.org/10. 1016/j.jmatprotec.2021.117133

16. Sønstabø JK, Morin D, Langseth M (2018) Testing and modelling of flow-drill screw connections under quasi-static loadings. J Mater Process Technol 255:724-738. https://doi.org/10.1016/j. jmatprotec.2018.01.007

17. Meschut G, Janzen V, Olfermann T (2014) Innovative and highly productive joining technologies for multi-material lightweight car body structures. J Mater Eng Perform 23(5):1515-1523. https:// doi.org/10.1007/s11665-014-0962-3

18. Grimm TJ, Parvathy GV, Mears L (2021) Friction element riveting: a novel aluminum to aluminum joining process. Proc Manuf 53:99-106. https://doi.org/10.1016/j.promfg.2021.06.015
19. Ma Y, Niu S, Liu H, Li Y, Ma N (2021) Microstructural evolution in friction self-piercing riveted aluminum alloy AA7075 T6 joints. J Mater Sci Technol 82:80-95. https://doi.org/10.1016/j. jmst.2020.12.023

20. Ni R, Hou W, Shen Y, Liu W, Cao F, Sun T (2021) Friction forge riveting: a new joining method for connecting $40 \mathrm{Cr}$ steel and TC4 titanium alloy. J Manuf Process 68:79-89. https://doi.org/ 10.1016/j.jmapro.2021.07.008

21. Römisch D, Kraus M, Merklein M (2021) Investigation of different joining by forming strategies when connecting different metals without auxiliary elements. Key Eng Mater 883:19-26. https://doi. org/10.4028/www.scientific.net/kem.883.19

22. B. Lossen, W. Homberg (2014) Friction-Spinning-Interesting approach to the manufacture of complex sheet metal parts and tubes. In: Mori, TIAKI Procedia Engineering of the 11th ICTP, vol 81. Elsevier, Nagoya, pp 2379-2384. https://doi.org/10.1016/j. proeng.2014.10.337

23. Homberg W, Hornjak D, Beerwald C (2010) Manufacturing of complex functional graded workpieces with the friction spinning process; ESAFORM, Brescia. https://doi.org/10.1007/ s12289-010-0924-8

24. Lossen B, Homberg W (2016) Friction spinning — twist phenomena and the capability of influencing them. 1769:070001. https:// doi.org/10.1063/1.4963454

25. Bach F, Schaper M, Nürnberger F, Krause C, Grydin O (2006) Bestimmung der Streckgrenze und der Hall-Patch-Konstanten des Vergütungsstahles 42CrMo4 unterschiedlichen Gefüges mittels Eindruckprüfungen. Materialwiss Werkstofftech 37:668-673. https://doi.org/10.1002/mawe.200600044

Publisher's Note Springer Nature remains neutral with regard to jurisdictional claims in published maps and institutional affiliations. 